\title{
THE EFFECT OF GST ON FARM MANAGEMENT INFORMATION SYSTEMS AND BUSINESS MANAGEMENT SKILLS
}

\author{
Name(s): Dr Tony Lewis \& Dr Christopher Bell \\ Affiliation(s) address(es): School of Business Systems, PO Box 63B, Monash University, Clayton Vic 3800 \\ Telephone: (03) 99059692 \\ Facsimile: (03) 99055159 \\ Email: tony.lewis@,infotech.monash.edu.au
}

\begin{abstract}
In 1989 New Zealand farmers were confronted by the introduction of a GST. Despite the short to medium term difficulties, many farmers have benefited from the experience. The introduction of the GST forced many New Zealand farmers to improve their record systems as they were required to submit more extensive and accurate information to comply with their new GST requirements. This increase in sophistication of their record systems also meant that farmers had a larger store of more accurate information available to support their farm business management decision-making. It is expected that the introduction of GST and PAYG reporting requirements in Australia is also acting as a catalyst in the evolution of dairy farm record systems and increase in dairy farmer's store of business management skills. This paper reports the results of a survey that describes the characteristics of dairy farm management information systems and indicates the business management skills that dairy farmers perceive they need to acquire in the short term in order to improve their farm management information systems and comply with their GST requirements. Overall, the importance of bookkeeping/ accounting skills is strongly related to BAS. However, the results also show that as the level of sophistication of dairy farm record systems grows the demand for business skills shifts from accounting/ bookkeeping skills to computer and analytical skills.
\end{abstract}

Keywords: Information Systems, GST, Business Management Skills.

\section{INTRODUCTION}

Tax reform, culminating with the introduction of Goods and Services Tax (GST), Pay As You Go (PAYG) and other new compliance requirements from the $1^{\text {st }}$ July 2000 has forced many dairy farmers to critically review their farm record systems and their own store of business management skills.

In 1989 New Zealand farmers were confronted by new reporting requirements bought about by the Lange Government's introduction of a GST. Despite the short to medium term difficulties, many farmers have benefited from the experience. The general experience of New Zealand farmers with their GST was typified in a report screened on the ABC's Landline program (Fullerton, 1999). The farmer interviewed stated that following improvements made in his accounting system to comply with the GST, he received an unexpected benefit - better quality information. This farmer now has an ongoing and increasing demand for quality information and has planned to make ongoing improvements in his farm record system in order to provide it.

This paper reports the results of a survey that describes the characteristics of dairy farm management information systems and indicates the business management skills that dairy farmers perceive they need to acquire in the short term. 


\section{BACKGROUND}

The ability of a Farm Management Information System (FMIS) to provide quality information is inhibited by the inadequacy in scope and structure of the underlying accounting system. Although many farm accounting systems are based on "commercial" manual recording systems or computer software cashbook/ accounting packages, they do not inherently generate accurate, relevant and consistent information. Initially, a farm business manager must design a "chart of accounts" that adequately reflects the true nature their own specific farm business. They must know how to properly identify, classify and record the various types of transactions related to their farm business entity. The farm business manager must also possess an adequate store of analytical skills in order to maximise the potential value of information generated by the farm accounting system. A farm business manager must therefore possess relatively high levels of business management knowledge and skills, especially bookkeeping/ accounting and analytical skills, in order for their farm businesses to realise the maximum benefit offered by a FMIS.

From a business management perspective, farm businesses are quite similar to other business types that have an underlying family social structure. These other business types commonly use the same popular cashbook or accounting packages used by farm businesses. For example, the common cashbook computer package Quicken is used by a variety of small business types including farmers. Quicken was promoted among farmer groups several years ago, and it is the most popular cashbook package used by Victorian farmers (Lewis, 1997). However, some serious inadequacies have been noted in client designed Quicken reports forwarded by a variety of small businesses to their accountant (Frank, 2001):

- Lack of appropriate account structures

- Transactions not correctly classified

- Missing or duplicated transactions

- Personal/ family transactions included with business transactions

- Basic accounting rules broken, i.e. debits recorded as credits

- Report structures that do not conform to accepted accounting standards

One Melbourne accountant (Frank, 2001) reported that some of his clients using Quicken had requested him to reduce his fee for completing their tax returns. They stated that they expected a reduction as they were now doing most of his work for him. In fact, the inadequacies in the Quicken reports rendered them useless for tax compliance purposes, and the accountant was forced to reconstruct accurate accounts before he could complete their tax returns. There is a procedure in the accounting profession called "shoebox" accounting. Clients place bank statements, cheque butts, invoices, receipts and the like, into a literal shoebox. Every year this shoebox would be upended on their accountant's desk. The accountant's task was to sort out the mess, construct accurate accounts and prepare the tax return. Many clients use of the Quicken program results in nothing more that an "electronic shoebox." The implication is that if output from these packages is inadequate for tax compliance purposes, then it is most probably inadequate for business analysis and business decision-making tasks because of a lack of scope and accuracy.

In the past, compliance reporting such as income tax was mainly the realm of accountants (Lewis, 1997). Farm business taxation information was commonly reconstructed from bank statements and other documents. Therefore, there was little incentive for farm business proprietors to keep complete and accurate records in respect to their compliance responsibilities. While it is true that a substantial number of dairy farmers maintained farm record systems that provided specific farm production or financial information, many lacked the scope and structure that would provide accurate and reliable information suitable for other business decision-making and reporting tasks. Again, there was little incentive for farm business managers to increase the scope and sophistication 
of their farm record systems, and the potential for these systems to enhance business outcomes was restricted accordingly.

Based on the New Zealand experience, it is anticipated that GST and PAYG reporting requirements in the Business Activity Statement (BAS) will actually encourage farm business managers to maintain more sophisticated records (Fullerton, 1999). A substantial increase in annual accounting fees is a keen incentive for farm business managers to establish and maintain their own improved farm record systems (Paterson, 2000), and there are severe penalties for inaccurate figures on the BAS. Many farm business managers may perceive that they currently lack specific skills needed to make improvements in their farm record systems. Therefore, GST and PAYG reporting requirements are also encouraging dairy farmers to review their personal store of business management skills.

The range of business management skills to be examined in the current study will fall into three basic groups. These are: bookkeeping and accounting skills, computer skills and analytical skills. It should be noted that computer skills are inclusive of Internet skills. It is also important to note that farm business managers will be asked to indicate the skills they believe they currently lack in order to successfully and efficiently complete their BAS without outside (the farm business) assistance. So, these will be the skills they perceive they need, which may or may not be the same as the skills they actually need.

\section{DETAILS OF THE SURVEY}

The survey sample was based on a random selection of 343 dairy farmer members of Dairy Food Safety Victoria. This sampling frame included the majority of registered dairy farmers operating in Victoria. Questionnaire forms were mailed to the selected dairy farmers in January 2002, from which 85 usable replies were received. This represents a response rate of approximately $25 \%$.

Questionnaires were addressed to the "prime decision maker" within each dairy farm business. This person is conceptualised as the one individual who has the primary task of making most business decisions, or where joint decision-making is common, the individual who normally has the casting vote. In an attempt to minimise the risk of bias in the results, the role of prime decision maker was not presumed to be either task or gender related.

In order to provide a context for the study, and to explore any relationship between skills and the dairy farming environment, several variables are used to generally describe the dairy farms in the study population. These include size of farm, number of years operated as a dairy farm business, minimum and maximum cows and maximum beasts maintained in the year preceding the questionnaire date, the type of operation i.e. whether a family business or not, and the number of people operating the dairy farm business. Also described are the accounting and production records maintained by individuals in the farm businesses or "outsiders" such as accountants and bookkeepers. Details include the decision-making purposes to which information from these records is put. A number of personal demographics related to prime decision makers and their spouse are used to round out the description.

The model used to describe farm businesses is the Farm Management Information System (FMIS) model (Lewis, 1998) (see Fig. 1). This model segments the study population according to the relative level of complexity and sophistication of their FMIS. A FMIS is defined as either accounting or production records maintained by individuals on the farm that provide information that is used to support farm management decision-making. There are four levels of complexity of FMIS. The first is No FMIS - where neither accounting nor production records provide information to support decision-making. The second is Manual FMIS - where accounting and/ or production records are maintained manually, without the aid of a computer system. The third is Computer- 
supported FMIS - Where some or all accounting or production records are maintained on a computer system, and the forth is Use of the Internet - where a computer system is used to gain access to the Internet to perform one of several tasks that include sending and / or receiving email, location of sources of information, and the purchase goods and services. This model depicts increasing sophistication in the underlying accounting or production record systems. Movement through the various levels is relatively contiguous, although there are exceptions. These exceptions are in the minority and do not form a significant group.

\section{FIGURE 1}

\section{Model of Farm Management Information Systems}

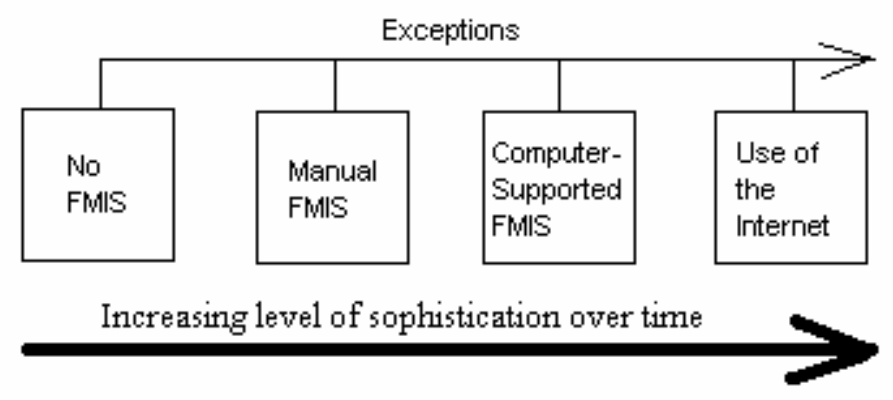

\section{RESULTS OF THE SURVEY}

The study population (those respondents with usable replies) are domiciled in all major dairy areas in Victoria, with $94 \%$ living on their farms. Average size of dairy farms is 203 hectares (minimum 25 , maximum 1100) carrying an average minimum of 94.6 cows and an average maximum of 236.6 cows within an annual cycle. Prime decision makers are generally well experienced in dairy farming with an average involvement of 22.4 years. However, not all respondents see a future in dairy with $34.5 \%$ stating that given the opportunity they would seek some other activity outside the dairy sector.

A majority, $98.8 \%$ of prime decision makers are involved in a family type business. Included in the definition of "family business" are sole operators, single-family operations, partnerships involving relatives and companies involving family members. There was only one non-family business respondent involved in a partnership of non-relatives. Farms are operated either by family members or a combination of family members and hired hands.

Average age of prime decision makers is 53.2 years, with a minimum of 29 years and maximum of 79 years. This statistic is consistent with other farmer groups, and indicates that, as a working group, people involved in dairy farming tend to be older than the average general working population. Prime decision makers tend to be male (78.6\%), but a significant proportion (21.4\%) are in fact female. Many past studies presumed the respondent farmer to be male and the prime decision maker. That is not to say that the current respondent females are the primary farmer - this presumption was carefully avoided in the construction of the questionnaire. But, is true to say that they are the prime decision makers within their own farm businesses. 
The majority of prime decision makers (61.9\%) have a secondary education, but trade/ certificate $(13.1 \%)$ and diploma courses $(15.5 \%)$ are also significant in the results. The interpretation is that while formal eduction remains at about the secondary level, more vocationally oriented postsecondary education, such as that available at TAFE and Agricultural Colleges is becoming more common

Farm record systems can be composed of a range of various records and reports. Each record system will be somewhat unique, but there is a commonly observable set of record and report types, a number of which can be found in all systems. Table 1 details frequency and percentage results for each accounting or production record or report type.

\section{Accounting Records}

TABLE 1

\begin{tabular}{|c|c|c|c|c|}
\hline \multirow[t]{2}{*}{ Record Type } & \multicolumn{2}{|c|}{ Ourselves } & \multicolumn{2}{|c|}{ Outsiders } \\
\hline & No. & $\%$ & No. & $\%$ \\
\hline Cash Book & 59 & 69.4 & 5 & 5.9 \\
\hline Reconciliation & 52 & 61.2 & 9 & 10.6 \\
\hline Other Important Ledger A/Cs & 35 & 41.2 & 1 & 2.8 \\
\hline A General Ledger & 32 & 37.6 & 6 & 7.1 \\
\hline Budgets & 42 & 49.4 & 14 & 16.5 \\
\hline Performance Report & 26 & 30.6 & 10 & 11.8 \\
\hline Profit \& Loss Statements & 28 & 32.9 & 34 & 40.0 \\
\hline Balance Sheets & 25 & 29.5 & 33 & 38.8 \\
\hline Tax Return & 11 & 12.9 & 67 & 78.8 \\
\hline
\end{tabular}

\section{Production Records}

\section{Record Type}

Livestock Records

Cropping or Paddock Management 68
Ourselves

No.

78

$\mathrm{n}=85$

Outsiders

No. $\%$

$\begin{array}{lll}91.8 & 4 & 4.7\end{array}$

Prime decision makers were asked to indicate if a particular record or report type was maintained by individuals within the farm family or by hired hands working on the farm ("ourselves"), or by "outsiders" such as accountants and bookkeepers. If a particular record or report type was not maintained, then a missing value was recorded in the results. Results in Table 1 detail the number and percentage of farm businesses with a particular record or report type maintained either by "ourselves" or "outsiders."

Table 1 shows that the simpler forms of accounting records are maintained primarily by "ourselves" while the more complex record type has an increasing proportion maintained by "outsiders." The majority of tax returns were prepared by "outsiders" mainly accountants. In general, accounting records are maintained by individuals within the farm business. Of course, it is possible that for a specific farm business some records may be maintained by "ourselves" and others, particularly tax returns, are prepared by "outsiders." 
There are two types of production records detailed in Table 1. Livestock records cover such things as details about individual animals, feed rations, breeding details or quantity or quality of production. Cropping information or paddock management includes records recording information such as cropping history, seed sown, fertiliser, herbicide or insecticide use. Many dairy farmers raise fodder crops and most have sown pasture in their paddocks. The majority of production records are maintained by individuals within the farm business.

In order for a farm management information system to be deemed to exist, information from a farm record system must be used to support farm business decision-making. Prime decision makers were also requested to indicate how information is used. For accounting records, four uses for information were detailed: (1) to show how much we have spent, or how much we have to spend, (2) to show how the farm business has run in the past so we can decide how to run it in the future, (3) to provide information to help us make big decisions, like purchase of equipment or whether to buy the farm next door, and (4) to provide information to help us decide what to do when problems come like drought, sickness, low prices and so on. For production records, four uses were also detailed: (1) to provide information to help decide which animal to breed, or which to cull, (2) to help decide which animals to market, (3) to provide information to help decide what to grow or when to grow it, and (4) to decide how much seed, fertiliser, herbicide or insecticide to use.

Results indicate that accounting and production records commonly do provide information to support farm business decision-making. The strong results for "how much spent, and how much we have to spend," $(78.8 \%)$ and "to help decide which animals to breed, which to cull" $(82.2 \%)$ appear to reflect the more universal nature of such decisions.

Results for the Model of Farm Management Information Systems are detailed in Table 2. Results show that the majority of farm businesses own a computer system, with the majority of computer owners having access to the Internet. The result of $48.2 \%$ for "use of the Internet:" was larger than expected, but not surprising owning to the fact that the majority of new computers now ship with modems, and connection to the Internet via a telephone line is a relatively simple procedure. It is interesting to note that only $7.9 \%$ of computer owners purchased a computer to gain access to the Internet - the majority $92.1 \%$ owned and operated a computer system before Internet connection. This result tends to support the notion of contiguous movement along the model, that is, the notion of gradual increase in sophistication of farm management information systems.

TABLE 2

Level of Sophistication of Farm Management Information Systems

\section{Level of Sophistication}

No FMIS

Manual FMIS

Computer-supported FMIS

Use of Internet

$\mathrm{n}=85$

\begin{tabular}{rl} 
Frequency & \multicolumn{1}{c}{} \\
1 & 1.2 \\
26 & 30.6 \\
17 & 20.0 \\
41 & 48.2
\end{tabular}

Prime decision makers were asked to indicate which of four skills that they believe they immediately need to improve in order to more easily complete their Business Activity Statement (BAS). These four skills are defined as follows: (1) Accounting/ bookkeeping skills - e.g. keep cash book better, expand your farm records, improve budgets, produce more accurate profit and loss statements, 
produce more details balance sheets etc., (2) computer skills - e.g. learn new software packages, use existing software better and so forth, (3) Internet skills - e.g. learn to find more information on GST and BAS, and similar activities, and (4) analytical skills - e.g. how to perform more advanced calculations using the information you already have available. Prime decision maker's responses are detailed in Table 3.

\section{TABLE 3}

Management Skills

Management Skill
Accounting/ bookkeeping
Computer
Internet
Analytical
$\mathrm{n}=85$
System Missing $=10$

$\begin{array}{lr}\text { Frequency } & \text { \% } \\ 41 & 54.7 \\ 19 & 25.3 \\ 2 & 2.7 \\ 13 & 17.3\end{array}$

The raw results in Table 3 suggest that less technically oriented skills of accounting/ bookkeeping are the most needed for completion of BAS. However, results are in part related to the level of complexity of farm management information systems. Table 4 repeats the results for Table 3 , but broken down by the level of complexity of farm management Information systems.

TABLE 4

Management Skill by Level of Sophistication of Farm Management Information System

No FMIS

Management Skill

Accounting/ bookkeeping

Manual FMIS

\section{Management Skill}

Accounting/ bookkeeping

Analytical

System Missing $=4$

Computer-supported FMIS

Management Skill

Accounting/ bookkeeping

Computer

Internet

$\begin{array}{ll}\text { Frequency } & \% \\ 1 & 100.0\end{array}$

$\begin{array}{lr}\text { Frequency } & \text { \% } \\ 21 & 95.5 \\ 1 & 4.5\end{array}$

$\begin{array}{lr}\text { Frequency } & \% \\ 9 & 60.0 \\ 2 & 13.3 \\ 1 & 6.7\end{array}$


System Missing $=2$

Management Skill

Accounting/ bookkeeping

Computer

Internet

Analytical
Frequency

$\%$

10

17

1
27.0

System Missing $=4$

$\mathrm{n}=85$

Despite there being only one observation for "No FMIS" results show that accounting/ bookkeeping skills are the most important to operators of non-computer supported FMIS, which tapers off as the level of sophistication of FMIS grows. Conversely, the importance of computer and analytical skills grow as the level of sophistication increases. The interpretation given to these results is that individuals within farm businesses that have relatively sophisticated farm management information systems have, in the main, acquired an adequate level of accounting/ bookkeeping skills, and other, more technically oriented skills become relatively more important. The most important set of skills for the completion of BAS appears to be accounting/ bookkeeping skills. The ability for farm businesses to complete their BAS from their own resources does appear to be related to the level of complexity of their farm management information systems.

\section{SUMMARY AND IMPLICATION}

The data suggests that the ability of Victorian dairy farm businesses to complete their BAS form from their own resources appears to be related to the level of complexity of their farm management information systems. In particular, accounting/ bookkeeping skills appear strongly related to BAS completion. The implication of the results relates to farm business decision-making - if it is accepted that larger and more sophisticated farm management information systems are better able to support farm business decision-making, then the introduction of BAS requirements is acting as a catalyst in improving farm management outcomes.

Results also highlight the importance of accounting/ bookkeeping skills. If the aim is to help increase the level of sophistication of farm management information systems, particularly the adoption of farm computer systems, then the transfer of accounting / bookkeeping skills should be made a priority for individuals in farm businesses that operate less sophisticated farm management information systems. For operators of the more sophisticated farm management information systems the transfer of computer and analytical skills should be made a priority.

\section{REFERENCES}

Fullerton, Ticky (1999) “GST New Zealand” Landline ABC TV June $6^{\text {th }}$ Frank, Graeme (2001) Interview, Melbourne May $9^{\text {th }}$ 
Lewis, Tony (1997) "Factors Influencing the Adoption of Computer-based Management Information and Decision-support Systems by Australian Farmers" Ph.D Thesis Swinburne University of Technology, Victoria, Australia

Lewis, Tony (1998) "Evolution of Farm Management Information Systems" Computers and Electronics in Agriculture, Vol 19, pp 233-248

Paterson, Jane (2000) "NFF head has faith in GST education" Landline ABC TV March $26^{\text {th }}$ 